\title{
THE APPROPRIATE LEARNING MODEL FOR CAREGIVERS OF DEPENDENT ELDERLY IN THAILAND COMMUNITY
}

\author{
KEERIN NOPANITAYA ${ }^{1}$, ACRAPOL NIMMOLRAT ${ }^{2}$, PIYANART CHATIKETU ${ }^{3}$ \\ \& ATICHART HARNCHARNCHAI ${ }^{4}$ \\ ${ }^{1,2,4}$ College of Arts, Media and Technology, Chiang Mai University, Chiang Mai, Thailand \\ ${ }^{3}$ Faculty of Dentistry at Chiang Mai University, Thailand
}

\begin{abstract}
The current situation with the number of elderlies in the world, including Thailand, has been increasing day by day. With the dependent elderlies in the community who are important in looking after closely because they are unable to help themselves, it is important to develop a group of personnel in the community to support thorough care. The government has the policy to provide caregivers with training for doctors, nurses, and physical therapists who come from the central hospital to be trainers and educating community volunteers to help solve the shortage of those caring for the dependent elderly group. However, from the field trips in participating with interviews and observing the caregiver's work after caregivers had finished training, most caregivers still lack important practical knowledge such as pressure ulcer management and physical therapy for treating dependent elderlies due to not having any practical experience, thus resulting in a lack of confidence when implementing the procedure. Therefore, the purpose of this paper is to develop a learning model on caring for the dependent elderly by using quality tools such as the AI 4D and SECI model to coordinate the collaboration. The quality of the work is also measured periodically during the process to ensure that caregivers use the knowledge and skill in their work as well as sharing and transferring the information to the team, especially with the community volunteers' group and relatives who need to provide proper care for the dependent elderly in the future.

KEYWORDS: Knowledge Management \& Thailand Community
\end{abstract}

Received: Jun 06, 2020; Accepted: Jun 26, 2020; Published: Aug 10, 2020; Paper Id.: IJMPERDAUG202015

\section{INTRODUCTION}

It was estimated from the year of 2001 to 2100 that it will be an elderly century because the world is stepping into an aging society whereas each country will age differently depending on their economic, social, technological, and medical progress. In the last 20 years, the world had a population of 5,735 million people with an age of being 60 years or more: approximately 540 million people, representing 9 percent of the world population [38] but in 2015, the world population structure has changed dramatically. From a total global population of approximately 7,349 million people, there will be 901 million people aging at 60 or older. 12.3 percent of the total population can say that "the world has advanced into an aging society" and in the year 2030, the world elderly population will increase to 1,402 million people or $16.5 \%$. Also, in 2050 , the world population of the elderly is expected to increase to 2,092 million people or 21.5 percent of the world population. In other words, in the next 32 years the world will step into "the complete aging society" [37].

Thailand has entered the aging society since 2005 and it is about to completely enter the aging society in 2021 [28]. Thailand's older population also represents the second-fastest-growing group of the elderly in Southeast 
Asia [21]. Currently, the proportion of the elderly accounts for 16 percent of the population nationwide. The number of older people increasing has resulted into an incidence of chronic diseases which are the cause of increased dependence. The late elderly ( 80 years and over) have increased dramatically so there will be increasing incidence of chronic diseases with their condition. Various chronic illnesses, especially joint pain and back pain, have been found up to 1 in 3 of other health problems as the cause of lacking ability or having little self-help that is heavily relied upon others. When the illness is severe and the disease progresses more [31] chronic illnesses deviate from the norm and causing the desired physical and mental to go through painful and distressing changes. Monitoring continuously enables one to observe and control the symptoms of the disease that leads to dependency [7].

Dependency is a condition that requires assistance from others in their lives and conducting various activities from the definition according to the Royal Institute of Population Studies [35]. In 2015 [33], the Ministry of Public Health conducted a health screening for 6,394,022 people and discovered that a group of elderlies are dependent on about 1.3 million people or 21 percent from the Thai population. The forecast from the situation of the elderly in 2006 [35] pointed out that by 2020, the population who are in their late 80 s and older has a tendency to increase, i.e. 1.6 million people or 2.4 percent. In 2030, it is projected that the increase will go up to 2.3 million people or 3.3 percent which will reflect health problems and the need to help provide health care for the elderly population, thus leading to an increase in the population of dependency age with regards to economic, social and health issue.

The inability to help oneself in the daily activities of the elderly will have a negative effect on the physical and mental health which causes the disease to be uncontrollable and have one's quality of life reduced. People with dependence need to receive appropriate care from caregivers who are mostly from family members, especially descendants and husband/wife [35]. This group of caregivers is very important in providing care for the dependent elderly in families because they help reduce the burden of care from the government in providing long-term care and help the elderly stay with their families and communities which can improve the quality of life of the elderly despite having the chronic illness. In Thailand, the trend in the care needs of dependent elderly is increasing due to the increasing age of the population, along with the chronic diseases and disabilities, while the capacity of the families to take care of them is decreasing, resulting in an increasing demand for institutional care [5]. Caregivers are strongly involved in healthcare management with patients who are elderly, in poor health, or who are burdened with a severe disease [42]. However, caring for dependent elderly in the family causes some problems in care especially if the cause of dependence is the result of the disease, accidents, or disabilities in which the caregivers do not have enough knowledge and skills to rectify the situation, therefore, causing more difficulties in looking after the caregiver's family.

Although at present the government has a policy to support the development of the Long-Term Care (LTC), which is providing health services in response to the needs of the dependent elderly. Although a training session was organized for caregivers of the dependent elderly by the department of health to work with a nurse manager it was learned that the number of caregivers were still lacking with the increasing number of dependent elderlies. The group who was responsible for watching over the dependent elderlies were family members that were not truly equipped for the capacity in protocol. This makes a huge impact on the caregiver in all aspects. On the physical side, the caregiver may become easily subdued to exhaustion, fatigue, not enough rest, which leads towards having more serious health problems on the elderly due to neglecting self-care. From a social perspective, with the caregivers having to spend a long time in caring for the elderly they miss out on the opportunities to participate in social activities which can lead to feeling lonely, anxiety, stress, and carrying such a heavy burden to bear with [29]. 
In terms of the economy, long-term care has led to increased family expenses, lower incomes, resulting in debt, and then caregivers lack the opportunity to pursue their careers or goals in life, however the caregivers know that the consequences are too high if they could not take care of the elderly [34]. Therefore, it is important to develop the capacity of caregivers to do their best for their dependent elderly. At the present, although caregivers have already passed the 70hour training course for elderly care from the department of health, it was found that they were still unable to perform their work [22-24, 30]. Wittenberg-Lyles et.al. [41] indicated that most of the caregivers are deficient in the basic knowledge and skills in providing quality care for a person with functional dependence as they lack confidence and felt unprepared to provide the care. Caregivers must develop a strong foundation of knowledge, extraordinary skills, and the right values and attitudes to effectively fulfill a patient's need [12].

\section{LITERATURE REVIEWS}

Appreciative Inquiry is regarded as a tool and energetic process to develop healthcare providers' connection, competence and expertise in elderly homes, through support administration, coaching, practice and consideration [27, 39]. The Appreciative Inquiry process support improvement that is depended on the healthcare provider's practical knowledge and vision of what they need to reform, and a participatory approach implements the opportunity for transformation from a bottom-up context [19]. Appreciative Inquiry (AI) is about creating a positive attitude, a method, a theory of action, a dialogue process, and a whole of system concept that brings together members of an organization to clarify, develop and integrate their visions about their joint endeavors. The purpose is to figure on something in the organization that works well and that can shift the organization to a higher level of goal acquisition to enhance the future of the organization [8]. Appreciative Inquiry consists of four insistent phases (discovery, dream, design, and destiny) recognized as the 4D-Cycle.

In the Discovery phase, this phase is interpreted as the time desired to consider the social potential of organizational life [8]. Attached in the inspection of the 'best of what is', this phase intends to deliver into focus what gives life and energy to people and the organization. The discovery phase gives a point of separation for dialogue and participated learning and change the balance of conversation from what is not working to what is. Whitney and Schau [40] described this phase as the time to learn, modify, and reproduce what works, and to have positive learning from informal potential innovations.

Dream phase is about visualizing results. Barrett and Fry [1] illustrate this phase as 'passionate thinking about a positive image of a desired and future state'. The dream phase is an encouragement for the group to extend the organization's positive core and imagine future possibilities. The objective of this phase is to share success stories and determine the core values taken by the group. The dream phase is a time for groups to imagine their future outside of the conventional outline of what was done in the past. Through the continued sharing of stories, the learning occurs. Typical visions can be classified, and sub-groups can be assembled to allow for more discussion and sharing.

Design phase is a high participation process in which the group reaches harmony and fits a vision for the organization as a whole [40]. During this phase, members are inspired to develop innovative procedure to deliver about the future they imagined in the dream phase. The objective is to articulate inspirational recommendations. These are figurative explanations illustrating what is best in the organization. Stated in the present tense, as if they were already a reality, inspirational recommendations explain how everyone can participate in the construct that is best for the future [14]. These recommendations set the organization for new and innovative practices. 
Destiny phase, the destiny phase is a 'construction of the future through innovation and action' [1]. This represents the period in which changes occur. The objective is to create actions around the inspirational recommendations, giving form to the values and ideals that were proposed. It is also a time when individuals or the group make engagement to implement and evaluate changes. The changes proposed appear from members' experiences in the organization, and the planned actions represent ways to duplicate and preserve the circumstances that made those experiences possible. Activities identified with accomplish behaviors in the destiny phase continually derive so they develop new ideas and dreams.

As health service managers, care managers should rapidly disseminate and share tacit and explicit knowledge with caregivers and other health professionals. Thus, they will contribute to enhancing the team's decision-making skills on care actions, which will directly affect the quality of care delivery.

Nonaka and Takeuchi [17] believe that knowledge can be split into, at least, two types: tacit and explicit. Tacit Knowledge is very personal and comes from one's experiences. From this, subjective feelings, instincts, and intuitions are made. It is difficult to transfer this kind of knowledge between people. Explicit Knowledge is information that can be formalized, documented, and therefore shared and transferred from person to person.

Another important component for sharing and transferring knowledge and skill which is related to health care is the place or space. Ba (equivalent to "place" in English) is a shared space for emerging relationships. It can be a physical, virtual, or mental space. Knowledge, in contrast to information, cannot be separated from the context it is embedded in ba. To support the process of knowledge creation, a foundation in ba is required. Each of the knowledge conversion modes is promoted by a specific "ba" [18].

The SECI spiral model is a well-known conceptual model that was first proposed by Nonaka [17]. It describes how explicit and tacit knowledge is generated, transferred, and recreated in organizations including health care providers. There are four modes of knowledge conversion in the Nonaka and Takeuchi model of knowledge conversion.

The socialization process transforms tacit to tacit knowledge. New knowledge is generated by communication, investigating, learning, or living in the same area. It is depended on face-to-face communication and shared daily experience. Teaching is produced by practical cases or on the job training. Organization can intake new knowledge from its environment.

Externalization is in conversion tacit knowledge to explicit. It is placed on a combination of tacit knowledge. Knowledge is created and shared in a group and it becomes group knowledge. It is accomplished by using words (by example, analogy and metaphor) or images. The result of the externalization process is explicit knowledge that is in understandable and illustratable form. It enables new knowledge creation.

A combination, as a third process, permit converting an explicit knowledge of groups to explicit knowledge of an organization. New knowledge is depended on a combination or an accumulation of explicit knowledge. The source knowledge is arranged, classified, and combined together. It can be achieved by meetings, conversations, exchange of documents through the organization [17]. This process must be investigated and integrated.

Internalization, as the final process of the SECI model, include exercises as learning and understanding of explicit knowledge. Explicit knowledge has developed into a part of an individual's knowledge. In other words, it can be described as re-assimilation of explicit knowledge back into daily operate. It is possible to be conscious not only by simple reading, 
but it must be done with a wakeful mind. Awareness is a crucial condition for the whole process. The new knowledge is sometimes explained as "secondary experience".

In the "middle-up-down" management model, Nonaka and Takeuchi attempt to meld the top-down and bottom-up approaches to organizational management but - unlike their peers of the 1990s - laud the mid-level managers as the key to successful organizational knowledge creation. For the authors, it is the mid-level manager who bridges top-level vision and ideals with the chaotic reality of front-line staff. In this regard, the mid-level manager might be seen as managing the "creative tension" between "where we are" and "where we ought to be." To do this, the mid-level manager must interpret and then develop mid-level concepts (e.g., business strategies, broad strokes of product lines, etc.) that reflect corporate vision and ideals but which allow enough flexibility for front-line experiences and creativity to flourish in terms of generating new knowledge [17].

Knowledge Engineers or mid-level managers take the lead facilitating the four modes of knowledge conversion: socialization; externalization; combination; internalization. In particular, Knowledge Engineers are particularly adept at externalization via developing mid-level concepts that align with but also interpret corporate vision and ideals within which front-line creativity and innovative ideas are brought to bear. Knowledge Engineers are also instrumental in amplifying knowledge across boundaries within and amongst organizations [17].

It is important to create an atmosphere of learning where learners are more actively involved in in-class activities, rather than sitting quietly and listening to the instructor for the duration of the class. The active learning approach, when employed in the classroom environment, helps instructors engage with students on a more real-time basis, encourages discussion of key concepts, and then answers learners' questions, as needed. Active learning defines as 'anything that involves learners in doing things and thinking about the things they are doing' In other words, for learning to be active, learners not only need to do something but also need to reflect on what they are doing [4]. Active learning provides many opportunities for learners to ask questions where they are unclear. It is not only concerned with classroom theory, but it also facilitates learners to practice their skills in the real world [20]. Active learning is learner-centered, where the individual's needs are more important than those of the group [10]. Active learning is a learner-centered teaching strategy that helps learners become actively engaged in their learning opportunities [32]. Learners become actively engaged in the topic when instructors create opportunities for their participation [36]. Designing active learning engagements means finding ways to merge what the learners will do with what the instructor will do [6].

\section{RESEARCH METHODOLOGY AND FINDING}

This is a qualitative research that uses participant action research (PAR). This research aims to study the community by focusing on problem analysis, studying how to solve the problem, following the process, and doing a follow-up evaluation by focusing on people as the center [13].

A 'snowball technique' was implemented by selecting a group of trustworthy experts to discuss about the research problems. At first, the researcher selected the expert person who has a deep understanding of the specific issues in the community and then asked the expert person to suggest another expert person. After that, the researcher requested the second expert person to suggest the next expert person until reaching the amount that the researcher needed. This research was selected from a group of 24 caregivers who have already trained for 70 hours with the Department of Health, and worked at the sub-district Health Promotion Hospitals which are the prototype of long-term care; a total of four hospitals 
and a group of four care managers $[2,15]$.

Data collection consisted of three methods which was a focus group discussion, participant observation, and indepth interview in naturalistic inquiries. It consisted of open-ended questions involving the personal profile, work experiences, and learning activities related to elderly care in the community, as well as list of motivation and obstacles in elderly care in the community. Participation and observation for the actual work of the caregivers were conducted at the workplace in the community such as the hospital and visiting homes [11].

Table 1: Caregivers' Demographics

\begin{tabular}{|c|c|c|}
\hline Demographic Factor & Number & Percentage $(\%)$ \\
\hline \multicolumn{3}{|c|}{ Gender } \\
\hline $\begin{array}{l}\text { Female } \\
\text { Male }\end{array}$ & $\begin{array}{c}24 \\
0\end{array}$ & $\begin{array}{c}100 \\
0\end{array}$ \\
\hline \multicolumn{3}{|c|}{ Age } \\
\hline $\begin{array}{l}45-54 \text { years old } \\
55-64 \text { years old }\end{array}$ & $\begin{array}{c}5 \\
19\end{array}$ & $\begin{array}{l}20.83 \\
79.17\end{array}$ \\
\hline \multicolumn{3}{|c|}{ Marital Status } \\
\hline $\begin{array}{l}\text { Married } \\
\text { Widowed / Divorced / } \\
\text { Separated } \\
\text { Never married }\end{array}$ & $\begin{array}{c}13 \\
5\end{array}$ & $\begin{array}{l}54.17 \\
20.83 \\
25.00\end{array}$ \\
\hline \multicolumn{3}{|c|}{ Education } \\
\hline $\begin{array}{l}\text { Less than high school } \\
\text { High school } \\
\text { Some collect } \\
\text { College graduate }\end{array}$ & $\begin{array}{c}6 \\
11 \\
4 \\
3\end{array}$ & $\begin{array}{l}25.00 \\
45.83 \\
16.67 \\
12.50\end{array}$ \\
\hline \multicolumn{3}{|c|}{ Employment Status } \\
\hline $\begin{array}{l}\text { Employed } \\
\text { Unemployed }\end{array}$ & $\begin{array}{c}17 \\
7\end{array}$ & $\begin{array}{l}70.83 \\
29.17\end{array}$ \\
\hline \multicolumn{3}{|c|}{ Elderly Care Experience } \\
\hline $\begin{array}{l}1-5 \text { years } \\
\text { More than } 5 \text { years }\end{array}$ & $\begin{array}{l}10 \\
14\end{array}$ & $\begin{array}{l}41.67 \\
58.33\end{array}$ \\
\hline \multicolumn{3}{|c|}{ Caregiving Location } \\
\hline $\begin{array}{l}\text { Local } \\
\text { Remote } \\
\text { Both }\end{array}$ & $\begin{array}{c}24 \\
0 \\
0\end{array}$ & $\begin{array}{c}100 \\
0 \\
0\end{array}$ \\
\hline
\end{tabular}

From table 1, after gathering data from the caregiver's profile, most of the caregivers in the community are female (100\%) similar to the study of Maurin and Boyd 1990, Thanakwang 2015, and Brodsky et al 2011. Most of the age range of caregivers are between 55 and 64 years (79.17\%). Furthermore, the employment status of caregivers was mostly employed (70.83\%) and the caregiving location of caregivers was mostly located in the local (100\%) as well. 
Table 2: Common Characteristics of Caregivers

\begin{tabular}{|l|}
\hline \multicolumn{1}{|c|}{ Positive Aspects of Caregiving } \\
\hline - Expectations for improving the health of the dependent elderly \\
- Having a good relationship with dependent elderly people in the community \\
- Desire to help dependent elderly in the community \\
\hline \multicolumn{1}{|c|}{ Negative Aspects of Caregiving } \\
\hline $\begin{array}{l}\text { - Have stress in work } \\
\text { - Receive less compensation than expected }\end{array}$ \\
\hline
\end{tabular}

Table 2 illustrates the data gathered from the interviews with caregivers in the community about the motivation and obstacles issues in elderly care in the community. There are interesting common positive aspects of caregiving for elderly in the community such as the expectation for improving their health, having a good relationship, and desire to help them as much as possible. However, there are also interesting common negative aspects of caregiving such as stress in work and receiving less compensation than expected.

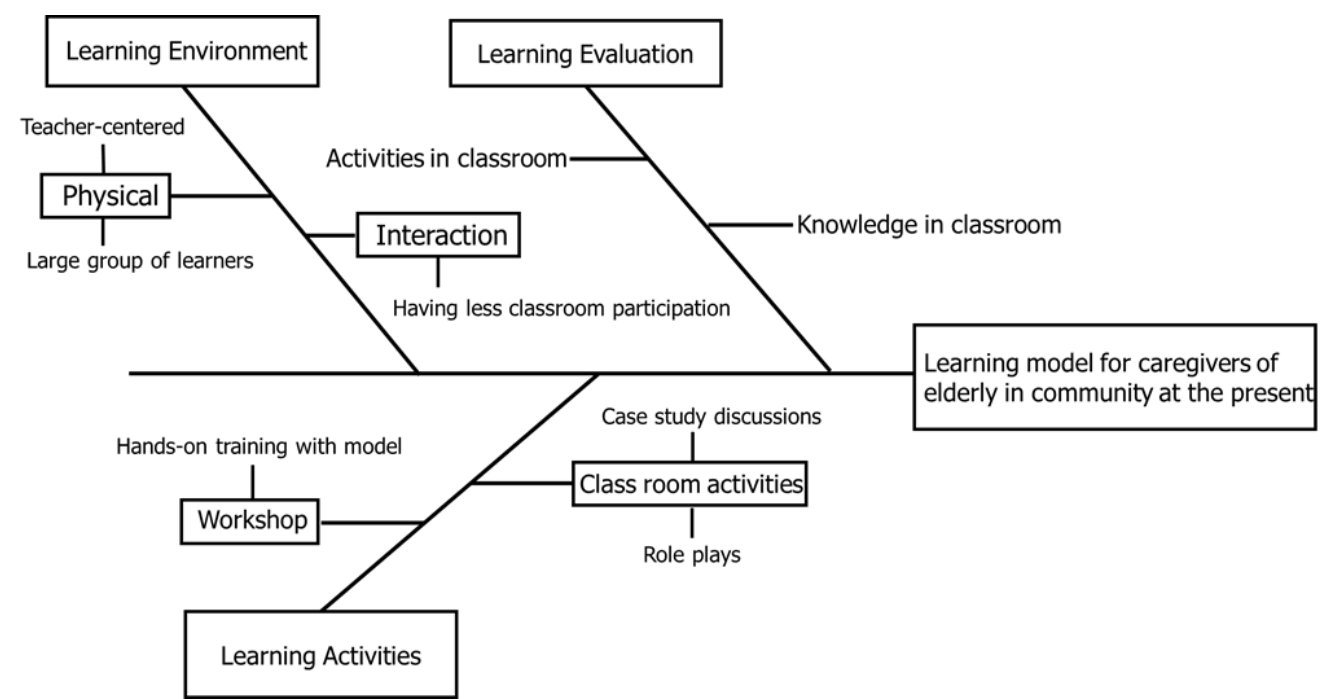

Figure 1: The Learning Model for Caregivers of the Elderly in the Community at the Present.

From the in-depth interviews and participation in caregivers observing about learning and working in caring for the elderly in the past community, it was found first that the learning environment was composed of a large group learning style through lecture training, whereas the lecturer (doctor, nurse or physical therapists) was from outside the organization. The person providing the lecture determines the content, activities and directions for teaching. The students and teachers have relatively little interaction in the classroom.

Second, it was discovered that for the teaching activities in practice, the instructor will perform a demonstration with the model such as showing procedures for pressure ulcer dressing with models. The drawback of this method is that students will not be able to get the real experience of pressure ulcer healing for patients thus causing them to have a lack of confidence in doing the procedures by themselves when it's time to encounter the real situations. Also, the teaching activities described various case studies that have been met for the learners and allowing students to play various roles such as being the ones providing the care to the dependent elderly or assuming the role as a dependent elderly.

Furthermore, the form of evaluation after learning is conducted within the classroom only. Both in the testing of theory knowledge and practice with the model caused students to lack the capacity in gaining a self-assessment of their learning from real life experience in doing it themselves with the dependent elderly. Therefore, learning to look after the 
dependent elderly should allow the learners be at the center and act as a patient and assessing the quality of work in real situations so that learners can apply knowledge and skills to take care of the dependent elderly in the community.

\section{THE PROCESSES OF LEARNING MODEL AND DISCUSSIONS}

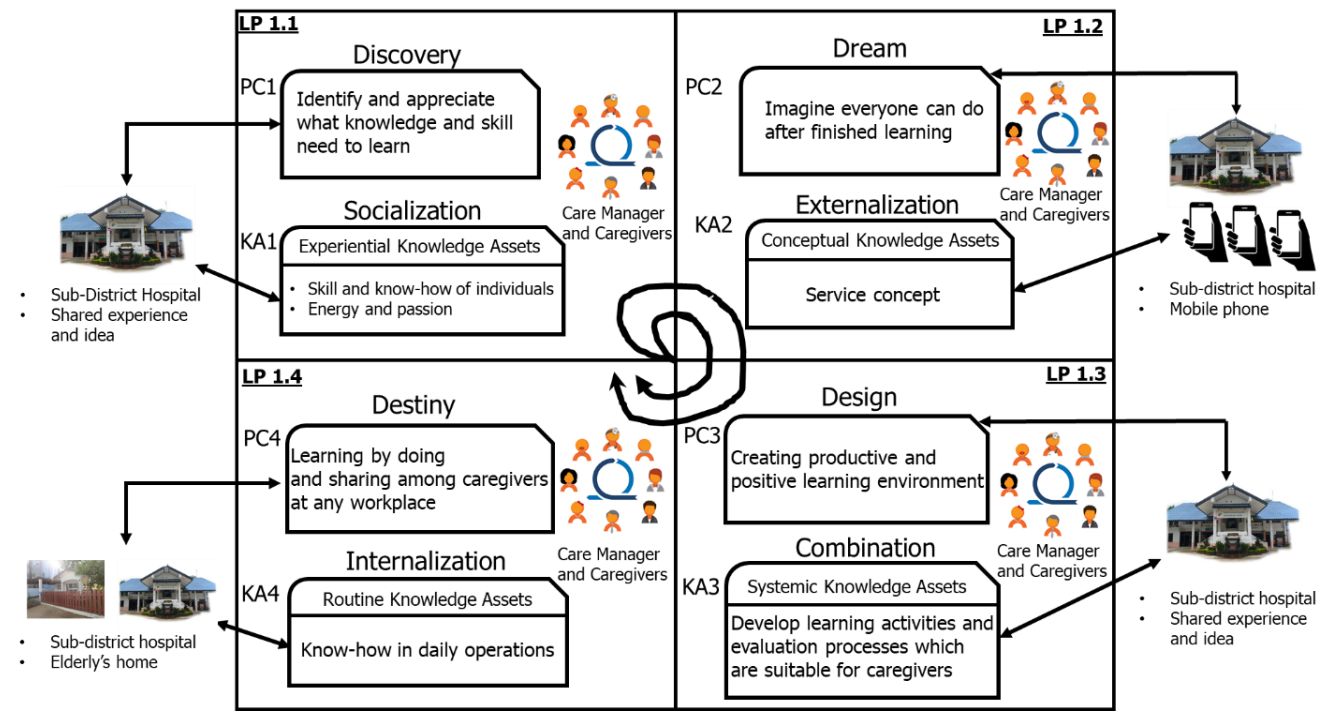

Figure 2: The Learning Process with AI 4D and SECI Model.

The process of learning model is divided into four phases corresponding with AI 4D and SECI process. In every learning phase, there will be a collaboration between the care manager and caregivers for conducting activities in knowledge exchange both content (explicit) and various work experience (tacit) related to caring for the dependent elderly together and the learning center is the caregivers themselves. This group of caregivers will show their careers' expectations of learning to have a clear picture of the learning. At first, the care manager will design the guidelines for posing questions to find various strengths and impressions of their work in the past time. Next, the care manager will begin to transfer knowledge, create learning activities that include the assessments from theoretical and practical learning. The learning environment will be happening inside and outside the classroom such as in the district health promotion hospital and the dependent elderly home. The details of the steps in the learning process will be explained in the next table 3 .

Table 3: The learning process with AI 4D and SECI model

\begin{tabular}{|l|l|l|l|}
\hline $\begin{array}{c}\text { Learning } \\
\text { Phases }\end{array}$ & \multicolumn{1}{|c|}{ Positive Change } & \multicolumn{1}{c|}{ Knowledge Assets } & \multicolumn{1}{c|}{$\begin{array}{c}\text { A Shared Space of } \\
\text { Emerging Relationships - } \\
\text { BA }\end{array}$} \\
\hline LP 1.1 & $\begin{array}{l}\text { PC1 - Identify and appreciate } \\
\text { what knowledge and skill need to } \\
\text { learn }\end{array}$ & $\begin{array}{l}\text { KA1 - Experiential Knowledge } \\
\text { Assets } \\
\text { Skill and know-how of individuals } \\
\text { Energy and passion }\end{array}$ & $\begin{array}{l}\text { Physical } \\
\text { Sub-district hospital Mental } \\
\text { Shared experience and idea }\end{array}$ \\
\hline LP 1.2 & $\begin{array}{l}\text { PC2 - Imagine everyone can do } \\
\text { after finish learning }\end{array}$ & $\begin{array}{l}\text { KA2-Conceptual Knowledge Assets } \\
\text { Service concept }\end{array}$ & $\begin{array}{l}\text { Physical } \\
\text { Sub-district hospital Visual } \\
\text { Mobile Phone }\end{array}$ \\
\hline LP 1.3 & $\begin{array}{l}\text { PC3 - Creating productive and } \\
\text { positive learning environment }\end{array}$ & $\begin{array}{l}\text { KA3 - Systemic Knowledge Assets } \\
\text { Develop learning activities and } \\
\text { evaluation processes which are } \\
\text { suitable for caregivers }\end{array}$ & $\begin{array}{l}\text { Physical } \\
\text { Sub-district hospital Mental } \\
\text { Shared experience and idea }\end{array}$ \\
\hline LP 1.4 & $\begin{array}{l}\text { PC4 - Learning by doing and } \\
\text { sharing among caregivers at any } \\
\text { workplace }\end{array}$ & $\begin{array}{l}\text { KA4 - Routine Knowledge Assets } \\
\text { Know-how in daily operations }\end{array}$ & $\begin{array}{l}\text { Physical } \\
\text { Sub-district hospital } \\
\text { Elderly's home }\end{array}$ \\
\hline
\end{tabular}




\subsection{Learning Phases 1.1}

The first phase is to start with discovery from AI 4D to develop a set of interview questions that can be used as a guide for conducting a structured dialogue with caregivers in the sub-district Health Promotion Hospitals. The selection of questions to be used is critical because these questions will begin to shape how caregivers see themselves and their community. According to the appreciative inquiry theory, people and/or organizations move in the direction of the questions they ask, therefore it is important that the topic of investigation is well-defined and that interview questions solicit positive responses focused on discovering root causes of success and best practices. In this case, the care manager decides to ask the positive question to caregivers such as "what knowledge and skills in elderly care have never been done by themselves before and needed in learning to support the elderly for having good health in the community.

After the care manager has posed a positive question to the caregivers' desire to learn to improve the community, the next step is to use the SECI model beginning with the socialization process which consists of creating and sharing tacit knowledge through interaction between individuals (mental ba), as it implies the conversion of tacit knowledge into tacit knowledge. In this case, the interaction occurs between individuals, i.e., experiences are shared between individuals. For this case, the interaction has occurred in the sub-district hospital (physical ba) between care manager and caregivers to find out the knowledge base that they have never done before in their job (Department of Health. (2013). Guideline for Training Caregiver 70-hour course for elderly care (Vol.6) Health promotion Division: Department of Health, Ministry of Public Health, which is from a list of knowledge bases such as physical therapy, pressure ulcer management, prevention of complications, personal hygiene and environmental management and housing for the elderly. All of the caregivers had already chosen pressure ulcer management for learning and practicing with their middle manager or knowledge engineer who is a care manager.

\subsection{Learning Phases 1.2}

Once the community's strengths and root causes for success are identified, the next step of AI 4D is to begin to imagine or "dream" about what the future would look like at its very best. What makes appreciative inquiry unique is that these dreams are grounded in the reality of the best practices already identified, so while a truly extraordinary vision may be developed, it is still achievable because it is based on extending existing best practices. Participants can increase their creativity when they are not confined to using words to express themselves. It also allows for individuals who have never before been asked or included in discussions about what they want for their community, to have a voice and share their visions. In this case, caregivers imagine everyone can do pressure ulcer management after finished learning with a care manager.

Next to the SECI model is the externalization process which involves turning tacit individual knowledge into an explicit collective one. In this mode of conversion, knowledge passes from the individual to the group with the use of metaphors, analogies, concepts, or models. Two factors are critical for externalization: (1) conversion of tacit to explicit knowledge using techniques that help individuals to express their ideas in words, with concepts or visually, (2) conversion of the tacit knowledge of caregivers and care manager into explicit knowledge. In this case, the knowledge conversion between care managers and caregivers have occurred in the sub-district hospital (physical ba) and communication via mobile phone (visual ba). For the use of metaphors, they decided to choose "the knowledge and skill of pressure ulcer management which anyone can do after finishing the learning". 


\subsection{Learning Phases 1.3}

The next step is to take the images of the future that have been created and put them into a format and structure that allows them to be acted upon. This has been done by recruiting a group of caregivers ( 6 persons) and care manager from the community to work as a "design team" in AI 4D to analyze the priority of contents, learning materials and activities of elderly care and put the vision for this priority into statements (also known as provocative propositions). In the sub-district hospital, this design team would be the foundation of their community and then each team's task can be used as a guide for action planning. In this case, the care manager has created a productive and positive learning environment for caregivers.

After that, in the combination process, it regards the systematization of explicit knowledge; there is a conversion of explicit into explicit knowledge. In this case, the knowledge surpasses from the group to the firm converting explicit knowledge into more complex forms. This is the phase that the groups may use for some external knowledge and combine it with the pre-existing internal one. Lessons learned and documented by different teams can be analyzed to generate new explicit knowledge for the firm. For this case, care manager has developed learning materials and activities by using an active learning program. The caregivers are the center of this learning throughout the course learned and also used the evaluation processes in pressure ulcer management which are suitable for caregivers to make sure that caregivers feel confident doing their task at the sub-district hospital and elderly's home (physical ba). Also, caregivers could share experience and idea (mental ba) during the class with their team and care manager all the time

\subsection{Learning Phases 1.4}

With the design team's work completed, it is now time to make the visions and goals a reality so this phase starts with destiny from AI 4D. When agreed commitments are implemented there is a continued commitment in learning, innovation, and delivery of the outcomes that all stakeholders care about. For this case, after the caregivers had already finished learning from the class, they will be learning by doing and sharing among caregivers at any workplace (physical ba) such as sub-district hospital and elderly's home. At the same time, the care manager has shared the tacit knowledge and coached with the caregivers' team about pressure ulcer management in a variety case that had been found in the community and evaluated the quality of their job at the end.

Finally, in the internalization process, it is a phase when explicit knowledge is converted into tacit knowledge. In this mode of conversion, knowledge flows from the firm to the individual. This type of conversion is related to "learning by doing". To internalize the individual needs to identify the relevant knowledge. In this case, caregivers will be using the know-how in daily operations about pressure ulcer management with the dependent elderly people at any workplace and care manager will be monitoring, coaching, and evaluating caregivers while they are preparing and treating pressure ulcers.

\section{CONCLUSIONS AND FUTURE WORKS}

The main objective of this paper is to develop the process of a learning model for caregivers of dependent elderly in the community by using AI 4D and SECI model to collaborative and sharing the knowledge between care manager who is the knowledge engineer or middle manager and caregivers who are the learner through the processes. For AI 4D, it has been used for stimulating caregivers by posing various positive questions that encourage good attitude and passion to learn with them which corresponds to Bloom (1964) who stated that while relationship is the attitude that is a catalyst for practice and knowledge it will not be used or acted until it has been given enough emphasis to be carried out. Next, the SECI model has helped in allowing the care managers and caregivers to study in detail about the progress of knowledge exchange in each of 
the teams. So, the integration between the AI 4D and the SECI model in each process of the learning model has been urged as the positive environment of learning and also created new knowledge and skill into the team. The knowledge and skill will be shared from the individual (care manager and each caregiver) to the group (caregiver's team). In the future, the caregiver's team can apply the knowledge and skill which they have got from their work experience whether it's in the subdistrict hospital or at the dependent elderly's home to their organization (community) by using knowledge transfer into other community volunteers' group. Finally, if the process of the learning model has continued on progressing with the knowledge and skill of others it will be possible to collect the new knowledge of experts who are from caregivers, community volunteers, or dependent elderly's family in the community.

\section{REFERENCES}

1. AL-ABADI, T. A. G. H. R. E. E. D. "Social Problems Facing the Elderly from the Viewpoint of Associates in the Day Care Homes in the City of Amman: A Field Study." International Journal of Environment, Ecology, Family and Urban Studies (IJEEFUS) 10. 2, Apr 2020, 9-18

2. Ahmed, Ayesha Sultana, and P. Radha Rani. "A Study on Sensory Limitations among Elderly, in the Selected Oldage Homes of Hyderabad City." Available at SSRN 3094275 (2017). IMPACT: International Journal of Research in Applied, Natural and Social Sciences (IMPACT: IJRANSS) 5. 12, Dec 2017, 13-20

3. Barrett F, Fry R (2002) Appreciative Inquiry in Action: The unfolding of a provocative invitation. In: Fry R, Barrett F, Seiling J, Whitney D. eds, Appreciative Inquiry, and Organizational Transformation: Reports from the Fields. Quorum Books, Westport $C T$

4. Biernacki, P., \& Waldorf, D. (1981). Snowball Sampling: Problems and Techniques of Chain Referral Sampling. Sociological Methods \& Research, 10(2), 141-163.

5. Bloom, B.S. (1964). Taxonomy of education objective: The classification of educational goals: Handbook II: Affective domain. New York: David Mckay

6. Bonwell CC, Elison JA. 1991. Active learning: creating excitement in the classroom. Ashe-Eric Higher Education Report 1. Washington, DC: George Washington University.

7. Caffrey RA. Family care of the elderly in northern Thailand: changing patterns. J Cross Cult Gerontol 1992;7:105-16.

8. Chang, Naiwen, and Yuan-Ho Hsu. "Social Security Reform in Aging Economy." International Journal of Humanities and Social Sciences (IJHSS) 6.3 (2017): 9-28.

9. Chandrika, K. B. "Need and intervention of social workers in public health care services and social development." International Journal of Humanities and Social Sciences 4.1 (2015): 57-62.

10. Chickering AW, Gamson ZF. 1987. Seven principles for good practice. AAHE Bull 39:3-7.

11. Cobin, J.M. Introduction, and Overview: Chronic Illness and Nursing in Hymen, R.B. and Corbin, J.M (eds.). Chronic Illness Research and Theory for Nursing Practice. New York: Springer Publishing Company, 2001.

12. Cooperrider D, Srivastva S (1987) Appreciative Inquiry in organizational life. In: Pasmore W, Woodman R. eds, Research in Organization Change and Development. JAI Press, Greenwich CT

13. Cooperrider, D. L., Whitney, D., and Stavros, J. M. (2008). The Appreciative Inquiry Handbook: For Leaders of Change. 2nd edn. Berrett-Koehle: San Francisco, United States of America. 
14. Duckworth E. 1987. The Having of Wonderful Ideas, and Other Essays on Teaching and Learning (New York, Teacher's College Press).

15. Gillis, A., \& Jackson, W. (2002). Research methods for nurses: Methods and interpretation. Philadelphia: F.A. Davis Company.

16. Given, B. (2001). Nurse practitioners: Issues within managed care environment. In J. McCloskey-Dochtermen \& H. KennedyGrace (Edss), Current Issues in Nursing, (6th ed), 358-366. St. Louis, MS: Mosby

17. Greenwood, D., \& Levin, M. (2001). Pragmatic action research and the struggle to transform universities into learning communities, In P. Reason \& H. Bradbury (Eds.), Handbook of action research. London: Sage

18. Hammonds S (1998) The Thin Book of Appreciative Inquiry. Thin Book Publishing, Texas

19. Heshmati F, Vanaki Z, Mohammadi I. Barrier to forming and implementing academic service partnership in nursing; a qualitative study. 2010.

20. Huggins D (2016) Enhancing nursing students' education by coaching mentors Nursing Management 23(1): 30-32.

21. Ikujiro Nonaka \& Hirotaka Takeuchi (1995). The Knowledge-Creating Company, Oxford University Press

22. Ikujiro Nonaka, Noboru Konno (1998) The Concept of 'Ba': Building a Foundation for Knowledge Creation Nonaka, California Review Management, Vol.40 No.3(Spring 1998): 40-54

23. James, I., Blomberg, K., Liljekvist, E., \& Kihlgren, A. (2015) Working together for a meaningful daily life for older persons: A participatory and appreciative action and reflection project-The lessons we learned. Action Research, 13(4), 336-353.

24. Leong, C. S. U., \& Clutter, L. B. (2015). Active learning improves nursing student clinical performance in an academic institution in Macao. Chinese Nursing Research, 2(2), 35-39.

25. Manasatchakun P, Chotiga P, Hochwalder J, Roxberg A, Sandborgh M, Asp M. Factors associated with health aging among older persons in Northeastern Thailand. J Cross Cult Gerontol 2016;31:369-84.

26. Nuankaew, P., Nuankaew, W., Phanniphong, K., Imwut, S., \& Bussaman, S. (2019). Students Model in Different Learning Styles of Academic Achievement at the University of Phayao, Thailand. International Journal of Emerging Technologies in Learning (IJET), 14(12), 133-157.

27. Nuankaew, W. S., Nuankaew, P., Teeraputon, D., Phanniphong, K., \& Bussaman, S. (2019). Perception and Attitude Toward Self-Regulated Learning of Thailand's Students in Educational Data Mining Perspective. International Journal of Emerging Technologies in Learning (IJET), 14(09), 34-49.

28. Nuankaew, W., \& Nuankaew, P. (2019). The Study of the Factors and Development of Educational Model: The Relationship between the Learner Context and the Curriculum Context in Higher Education. International Journal of Emerging Technologies in Learning (IJET), 14(21), 205-226.

29. Nyback M-H (2013) A constructivist approach to teaching and learning at the Degree Programmed in Nursing at Novia University of Applied Sciences. Novia University of Applied Sciences. Serie R 6/2013. Retrieved from goo.gl/x6ehta.

30. Oliva P (2009) Developing the Curriculum (7th Edn.). Boston: Pearson, Allyn \& Bacon.

31. Phanniphong, K., Nuankaew, P., Teeraputon, D., Nuankaew, W., Boontonglek, M., \& Bussaman, S. (2019). Clustering of Learners Performance based on Learning Outcomes for Finding Significant Courses. 2019 Joint International Conference on Digital Arts, Media and Technology with ECTI Northern Section Conference on Electrical, Electronics, Computer and Telecommunications Engineering (ECTI DAMT-NCON), 192-196. https://doi.org/10.1109/ECTI-NCON.2019.8692263 
32. Prasatkul, P., et al. The Situation of Thai Elderly in 2015. Bangkok: Population Research Institute and Society, Mahidol University Foundation for Thai Elderly Research and Development Institute (MAS), 2016

33. Rattanawimol, K. Role Strain of Family of Dependent elderly: A Case Study of the Municipality of Sukhothai Province. Thesis of Master Degree in Nursing Science, Faculty of Nursing. Bangkok: Chulalongkorn University, 2002.

34. Rithamrongsawat S, Suriyawongpaisan P, Kaseamsub W, Aekpalakorn W, Lerapan B. The research project for developing long-term care for the dependency in older adults under universal coverage scheme. Bangkok: Community medicine department, Faculty of Medicine, Ramathibodi Hospital; 2018.

35. Sasat, S. Nursing Care for the Elderly: Common Problems and Care Guidelines. Bangkok: Chulalongkorn University Press, 2006.

36. Shin H, Sok S, Hyun KS, Kim MJ (2015) Competency and an active learning program in undergraduate nursing education. Journal of Advanced Nursing 71(3): 591-598.

37. Sirikampeng, A.\& Posing, P. The Long-Term Care for the Elderly Dependency on Thailand 4.0. Dhammathas Academic Journal, 2017;17(3):235-245.

38. Sreehapak, S., et al. Impact and Burden of Long-Term Care for Thai elderly. Nonthaburi: Health Systems Research Institute, Bureau of Policy and Strategy, Ministry of Public Health, 2014.

39. Sreethamrongsawad, S. \& Boonthamjalern, K. Synthesis of Long-term Care System for the Elderly in Thailand. Bangkok: Foundation for Thai Elderly Research and Development Institute, 2010.

40. Stevenson E, Gordon H (2014) Students as active learners and teaching partners in the clinical setting. Nurse Educator 39(2): 52-53.

41. United Nation. (2015). World populations ageing 2015. New York: Author.

42. United Nations Population Fund. (2012). Ageing in the twenty-first century: A celebration and a challenge. New York: Author.

43. Wadensten, B., Engholm, R., Fahlström, G., \& Hägglund, D. (2009). Nursing staff's description of a good encounter in nursing homes. International Journal of Older People Nursing, 4(3), 203-210.

44. Whitney D, Schau C (1998) Appreciative Inquiry: An innovative process for organization change. Employ Relate Today Spring: $1-9$

45. Wittenberg-Lyles, E., Demiris, G., Oliver, D.P. \& Burt, S. (2011). Reciprocal suffering: Caregiver concerns during hospice care. Journal of Pain and Symptom Management. DOI: 10.1016/j.jpainsymman.2010.04.026

46. Wolff JL, Roter DL. (20008). Hidden in plain sight: medical visit companions as a resource for vulnerable older adults. Archives of Internal Medicine.168(13): 1409-1415. 


\section{AUTHORS PROFILE}

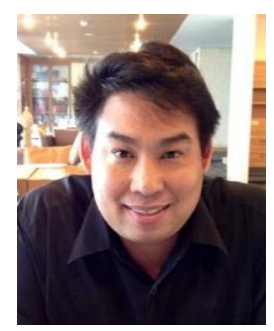

Keerin Nopanitaya, he received a Bachelor of Computer Engineering degree in 1996 from Kasetsart University, a Master of Telecommunication Management degree in 2002 from Thammasat University. He is currently a students at College of Arts, Media and Technology, Chiang Mai University, Chiang Mai, Thailand. His research interests is in knowledge management.

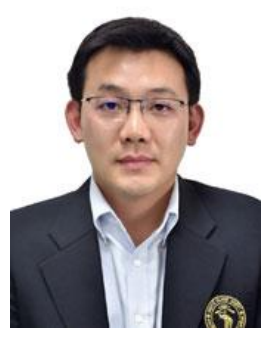

Acrapol Nimmolrat, he is currently a lecturer at College of Arts, Media and Technology, Chiang Mai University, Chiang Mai, Thailand. His research interests is in Business Intelligence.

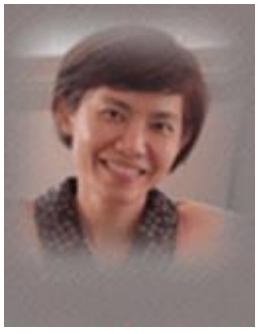

Piyanart Chatiketu, she is currently a lecturer at the Faculty of Dentistry at Chiang Mai University, Thailand. Her research interests is in knowledge management.

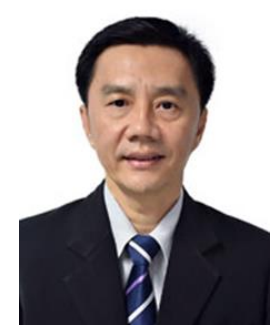

Atichart Harncharnchai, he is currently a lecturer at College of Arts, Media and Technology, Chiang Mai University, Chiang Mai, Thailand. His research interests are in Information and Communication Technology in Knowledge Management, Knowledge Based System. 